\title{
Cultuur, sociologie en de verbeelding van bevolkingsgroepen
}

\author{
Rogier van Reekum
}

SOC 12 (1): 123-139

DOI: 10.5117/SOC2016.1.REEK

Every form of identification that does not resolve into identity is also a form of disidentification:

Yes, you can call me by that name, but I am not really captured by that name; whoever I am does not correspond to the norms conveyed by the name you call

me;

even if I answer to the call, something in me resists or exceeds the way you call me,

and yet I am here, responding.'

- Judith Butler (2015: 33)

Het relletje rondom Sywert van Liendens uitspraken in het amusementsprogramma De Wereld Draait Door van 12 januari 2016 laat goed zien hoe moeilijk het is om iets over cultuur te zeggen in het Nederlandse publieke debat. Wat was er aan de hand? Sywert van Lienden besprak, in de context van tamelijk gespannen, deels racistische debatten over seksueel geweld tegen vrouwen, een artikel uit Mens \& Maatschappij. Anton van Wijk en Arjan Blokland publiceerden in 2006 een exploratief onderzoek waarin ze 'etniciteit' met 'seksuele delinquentie' correleerden. Van Lienden wilde met dit onderzoek nu eens zonder gedraai een verband leggen tussen cultuurverschil en seksueel geweld. Dit liep slecht voor hem af, omdat hij een en ander verkeerd weergaf en het onderzoek sowieso van tendentieuze betekenis was voor het lopende debat. Van Lienden werd gecorrigeerd en het amusementsprogramma bekritiseerd: de feiten willen melden was mooi, maar moest wel goed gebeuren. ${ }^{1}$

De hele episode - van kwestie, naar onderzoek, naar tv-uitzending, naar correcties en kritiek - is tekenend voor het doolhof waarin publiekelijk spreken over cultuur gevangen zit. Dat komt vooral omdat met het woordje 'cultuur' in feite niet cultuur bedoeld wordt. Cultuur wordt be- 
spreekbaar gemaakt door het over iets anders, namelijk 'bevolkingsgroepen', te hebben: Bevolkingsgroepen kunnen en mogen verantwoordelijk gehouden worden voor problemen. Zij hebben of zijn het probleem, want zij hebben of dragen een cultuur. Deze groepslogica is diep gecementeerd in het publieke denken, spreken en ruziën over kwesties van in- en uitsluiting, migratie en burgerschap (Barker 1981; Essed 1994; Wekker en Lutz 2001; Schinkel 2007).

Heeft het zin om cultuur aan de hand van 'bevolkingsgroepen' te analyseren en welke rol speelt het sociologisch onderzoek naar 'bevolkingsgroepen' hierin? Van Lienden besloot het relletje door te beweren dat alle methodologische keuzes politiek zijn. Het eerste zinnige dat hij te melden had. Helaas bedoelde Van Lienden daarmee dat hem een methodologische voorkeur niet kwalijk genomen kon worden. Zoals ik zal betogen is dat precies het omgekeerde van wat deze opmerking inhoudt.

\section{Het cultuurprobleem}

We zouden nog verder terug kunnen gaan (zie Jones 2007; Gouda 2008; Stoler 2010; Weiner 2015), maar de meest recente uitwerking van een groepslogica ten aanzien van migratie en burgerschap is te vinden in de jaren zeventig van de vorige eeuw (Tinnemans 1994; Bonjour 2009; Scholten 2011; Uitermark 2012). Het is in die jaren dat een publieke taal is ontwikkeld voor het diagnosticeren van, wat in die jaren nog geregeld, 'de multiraciale samenleving' werd genoemd. 'Cultuur' moest in dezen diagnostiek aangeven in hoeverre iedere 'bevolkingsgroep' - Surinamers, Antillianen, woonwagenbewoners, vluchtelingen etc. - was toegerust op het zelf oplossen van economische en sociale problemen, gezien de economische herordening na de oliecrisis, de dekolonisering en een keuze voor een 'activerende' verzorgingsstaat (Rath 1992; Vink 2007; Schrover 2010; Lucassen en Lucassen 2011, 2015; Van den Berg 2016). Deze taal werd dan ook onderdeel van een beleidsprogramma - het minderhedenbeleid - dat wederzijdse bestendiging van etnisch-raciale en sociaaleconomische segregatie moest ontzenuwen (Molleman 2003). Het doel van dit beleid was de creatie van een 'zelfredzame' bevolking die de obstakels van armoede en traditie zou overwinnen (Duyvendak et al. 2009). 'Cultuur' en 'etniciteit' hadden dus altijd al hiërarchische betekenissen, analoog aan meer sociaaleconomische groepskwalificaties (De Regt 1984; Derksen en Verplanke 1987; vgl. Verwey-Jonker 1973). 'Cultuur' betekent in de publieke taal van Nederland storing, obstakel, achterlijkheid en probleem. Wie wel toegerust 
is op 'de nieuwe tijd' heeft geen 'cultuur', in elk geval geen 'cultuur' waar publiekelijk over gediscussieerd hoeft te worden (zie ook Yanow en Ter Haar 2013).

In het Nederlandse debat wordt al decennia onophoudelijk over deze 'cultuur' gesproken en daarbij speelt voortdurend de suggestie dat dat eigenlijk niet mag (Prins 2004; vgl. Couwenberg 1982; Vuijsje 1986). Dit zogenaamde gebod komt niet voort uit een antiracistische, cultuurrelativistische of postkoloniale zelfkastijding, alsof het publieke debat een psychoanalytisch gesprek met het Volk is (Essed 1984; Tinnemans 1994; Kennedy 1995; Gabriels 2001; Van der Valk 2002; Essed en Nimako 2006; Jones 2007; Uitermark 2012; Duyvendak et al. 2013; Laarman 2013; Van Reekum 2014). Het 'eigenlijk niet mogen' is een frase in een opkomend verhaal over Nederlandschap dat vanaf de jaren zeventig het imaginair van een christelijk koninkrijkje met burgerlijke karaktereigenschappen gaat vervangen (Mellink 2014; Van Reekum 2016).

In dat nieuwe verhaal is de Nederlander bovenal het vrijgevochten individu. Dit individu begeeft zich voortdurend in wisselende en horizontale relaties, precies wat de nieuwe 'economie' en de ontzuilde 'vrije tijd' van hem verwacht. 'Cultuur' is dan ook het gebrek om met een dergelijke 'flexibiliteit' om te gaan: 'traditionele gezinsverhoudingen', 'vrouwenonderdrukking' en 'zelfsegregatie'. Daar waar 'cultuur' wordt aangetroffen, mag en moet de vrijgevochten Nederlander zich verheffen boven de nieuweling. Maar daar waar de nieuweling nu juist de drager blijkt van nieuwe manieren en relaties, van mondaine flexibiliteit, moet de Nederlander deze zonder weerstand incorporeren. Zie daar het dilemma van het Nederlandse nationalisme zoals dat vanaf de jaren zeventig de publieke opinie is gaan tekenen (Van Reekum 2014).

Religie en seksualiteit, in onderlinge verstrengeling, zijn de belangrijkste kwesties geworden waarmee 'achterlijkheid' van 'wereldsheid' wordt onderscheden (Mepschen et al. 2009; Verkaaik 2009). Daartoe zijn lange tijd ras en racisme als kwesties aan de kant geschoven: antiracisme wordt in het Nederlandse debat bekritiseerd als een manier om gelijken het zwijgen op te leggen, terwijl het 'vrijuit spreken' over zelf en anderen nu juist het nieuwe ideaalbeeld is geworden (Van Dijk 1992; Bosma 2013; Van Reekum 2016).

And yet, between the yes and the no, both conditioned by a firm sense of identification, is there not a critical alternative that focuses less on what you call me than on what calls when you call?

- Judith Butler (2015: 33) 


\section{Methodologisch etatisme}

Het is in dit probleemveld dat sociaalwetenschappelijke interesse voor 'etnische cultuur' vorm heeft gekregen. Ze is vooral een zoektocht naar de te koesteren andersheid en te corrigeren rigiditeit van nieuwkomers, waarbij het laatste de overhand heeft. Dat uit zich in een veelheid van gevalsstudies naar 'gemeenschappen' (bijvoorbeeld Buiks 1983; Vermeulen 1984; Ferrier 1985; Van den Berg-Eldering 1986; Van der Werf 1995) maar vooral vanaf de jaren negentig in grootschalig etno-statistisch onderzoek naar criminaliteit, gezondheid, opleiding, werkloosheid, contacten, opvattingen en extremisme. Dit onderzoek naar 'bevolkingsgroepen' is publiekelijk toegankelijk, breed gefinancierd, bepalend geweest voor beleidsvorming, voortdurend aangehaald in de media en, bovenal, infrastructureel mogelijk gemaakt door de Nederlandse overheid (Groenendijk 2008). Van enig taboe is geen enkele sprake.

Het cultuurprobleem wordt met dit onderzoek voorgesteld als een vorderend proces met voor- en achterlopers, niet als een verandering van condities waarbinnen mensen met elkaar strijden over wat goed, waar en schoon is. Onderzoekers die zich verzetten tegen deze depolitisering hebben ontegenzeggelijk tegenwerking ondervonden. Dat is geen bewijs voor al dan niet 'links' taboe - alsof het bestaande onderzoek niet gedaan werd om de relatieve achterlijkheid van 'bevolkingsgroepen' te bepalen -, maar bewijs voor de innige relatie tussen sociaalwetenschappelijk onderzoek en een paternalistische bestuursmentaliteit (Schinkel 2007; Scholten 2011; Entzinger en Scholten 2015; Van Houdt 2014).

Het is de Nederlandse overheid die in samenwerking met onderzoekers een nationale registratiestandaard heeft ontwikkeld - de Gemeentelijke Basis Administratie (GBA) -, waardoor 'geboorteland' statistisch gecorreleerd kan worden met een veelheid van andere variabelen. Deze poel aan data wordt nu al ruim twintig jaar gebruikt om van alles en nog wat door de etnische lens te belichten. Over de zin en onzin van dergelijk onderzoek wordt onder academici wel gedebatteerd (zie bijvoorbeeld Krebbekx et al. 2013), maar dit heeft niet of nauwelijks invloed op het publieke debat of de beleidsontwikkeling. Daar geldt de groepslogica van het Nederlandse cultuurbegrip: er zijn sowieso 'bevolkingsgroepen', statistisch herkenbaar aan hun 'geboorteland', en deze laten in vergelijking met de 'autochtone' nulmeting een bepaalde afwijking zien. Die afwijking moet, zo gebiedt het vrijgevochten individu, 'benoemd worden'. In dit licht doen 'Marokkanen het beter dan Turken', doen 'Antillianen het nog steeds even slecht als vijf 
jaar geleden' en lijken 'Polen hetzelfde niveau als autochtonen bereikt te hebben'. Etno-statistiek is prestatiemeting.

Wat al deze statistische verbanden precies betekenen, weet eigenlijk niemand. Dat komt vooral omdat er in dit etno-statistisch onderzoek geen gedegen conceptualisering van etniciteit bestaat en, vervolgens, ook niet voor de relatie tussen 'etniciteit' en 'cultuur'. Anders gezegd: er wordt nooit afdoende gearticuleerd welk theoretisch begrip met 'geboorteland' gemeten wordt. Meestal wordt 'geboorteland' niet gebruikt als een methodologische benadering van een theoretisch concept, zoals inkomen dat is voor 'klasse' of het aantal boeken in een huishouden dat is voor 'cultureel kapitaal'. Nee, 'geboorteland' is - als vanzelf - etniciteit en etniciteit wordt, vooral in het publieke debat, voor 'cultuur' gehouden. 'Cultuur' betekent immers 'wat anderen hebben' en kan dus enkelvoudig aan de migratiegeschiedenis van naasten gelijkgesteld worden.

Onderzoekers menen dikwijls dat de sluitende correspondentie tussen meting en concept een voordeel is (vgl. Verweij 1997). Dit is uiteraard een vergissing. Wie denkt dat een thermometer een goed meetinstrument voor temperatuur zou zijn omdat het gedrag van de thermometer zou bepalen wat temperatuur is, mag zijn wetenschapsfilosofie-tentamen overdoen. Dat temperatuur een theoretisch concept is buiten haar methodische en technische operationalisering, is voor het bedrijven van normale wetenschap volstrekt noodzakelijk (De Vries 1977). Zo niet in het Nederlandse etnostatistisch onderzoek: daar definieert men rustig het concept aan de hand van haar meetbaarheid. ${ }^{2}$

Onderzoekers houden tegen deze aanmerkingen voet bij stuk door te stellen dat voor inkomensgroepen, gender of leeftijdscohorten toch ook mensen onder een geaggregeerd label gegroepeerd worden. Er moet nu eenmaal een categorie gemaakt worden. Maar de vraag is helemaal niet of er complexiteit gereduceerd wordt, maar hoe. Er spelen hier twee zaken.

Ten eerste moet de wijze waarop een meetinstrument complexiteit reduceert in verhouding staan tot een theorie over het te meten concept. Door respondenten te verdelen in mannen en vrouwen denken wij redelijk goed te weten wat we meten, omdat we de theorie aanhangen dat in de werkelijkheid mensen ook op die manier beoordeeld worden. Precies daar en waar dat niet opgaat, is het categoriale genderonderzoek in gebreke. Geregeld dus. Door respondenten te verdelen in inkomensgroepen denken wij redelijk goed te weten wat we meten, omdat we de theorie aanhangen dat kapitaal uit te drukken is in geld. Daar en waar dat niet zo is, wordt het maken van inkomenscategorieën zinloos. Geregeld dus. Voor etniciteit is het feitelijk niet anders: men veronderstelt redelijk goed te weten wat men 
meet met 'geboorteland', omdat men - hoewel meestal stilzwijgend en ongekwalificeerd - de theorie aanhangt dat relatieve ongeschiktheid voor 'het moderne leven' is uit te drukken in 'geboorteland'.

Deze onuitgewerkte theorie is overigens een afgeleide van de moderniseringsthese. Daarin wordt wat geldt als 'moderniteit' - burgerlijke gezinsverhoudingen, liberale instituties, kapitalisme, vrijhandel, de ideologische dominantie van de hogere middenklasse etc. - tot norm verheven en buiten het onderzoek geplaatst (zie ook Somers 1995a, 1995b). Juist daarom produceert dergelijk onderzoek enkel variaties op de conclusie dat 'problemen' te wijten zijn aan de onvolkomen 'modernisering van bevolkingsgroepen' (Boersma en Schinkel 2015). De mogelijkheid dat 'modernisering' of 'autochtonie' zelf problemen creëren, is methodologisch uitgesloten (als het al bevraagd wordt). Verder is aan de hand van etno-statistisch onderzoek niet te bepalen of het inderdaad zo is dat 'geschiktheid' afdoende of betekenisvol samenvalt met 'etniciteit-qua-geboorteland'. Daarvoor zou 'geschiktheid' een andere operationalisering moeten krijgen, maar dan vervalt - in dezen - de noodzaak om naar 'bevolkingsgroepen' te aggregeren.

Ten tweede veronderstelt aggregatie naar 'bevolkingsgroep' dat etniciteit op een bepaalde manier werkt. Er bestaat een lijvige en gevarieerde onderzoeksliteratuur die aantoont dat 'een etniciteit' in het leven van mensen geenszins werkt zoals bijvoorbeeld 'een inkomen' dat doet (bijvoorbeeld Brubaker 2004; Baumann 1996; Eriksen 2012; Wimmer en Glick Schiller 2002; Comaroff en Comaroff 2009). De waarde van 50.00o euro hoeft - dankzij staatsmacht - niet onderhandeld te worden en is daarom vergelijkbaar met een andere 50.00o euro. Haar gebruik is over de gehele geldeconomie inwisselbaar. De betekenis van een etniciteit is nu juist voortdurend in onderhandeling door mensen zelf. Niet alleen 'Marokkanen' bepalen wat 'Marokkaans' is, maar ook vele anderen. Deze anderen zijn op hun beurt anders omdat ze, alweer met anderen, uitvogelen wat het is om 'niet-Marokkaan' te zijn (zie vooral Hall 1996). Bovendien is er onder mensen die zich op enig moment 'Marokkaans' weten, voortdurend gedoe over wat het 'Marokkaan zijn' bepaalt. Dat gedoe is het werk dat etniciteit doet in het leven van mensen. Onderzoek naar de werking van etniciteit moet gericht zijn op vormen van grenswerk (Lamont en Molnar 2002; Baumann en Gingrich 2004).

De complexiteit van dat werk wordt bijzonder slecht gereduceerd door te aggregeren naar 'bevolkingsgroepen', omdat deze methode zelf een vorm van grenswerk in werking zet en daarmee de rest overstemt (Schinkel 2013; zie ook Hacking 2007; Ruppert 2012). De methode volgt namelijk één bepaalde ideologie en zienswijze ten aanzien van etniciteit, waardoor de 
werking van etniciteit - het maken en trekken van grenzen - onzichtbaar wordt.

De ideologie die hier gevolgd wordt, zegt dat een ieder primair één etniciteit heeft ${ }^{3}$ en dat deze etniciteit identiek moet zijn aan zichzelf. De idee van discrete mensengroepen is natuurlijk, laten we het netjes houden, weerlegd. Maar dat betekent niet dat groepen niet voortdurend gemaakt worden (Fields en Fields 2012; M'Charek 2013). Dit groepen-maken is wat onderzocht moet worden.

De zienswijze die hier gevolgd wordt, is de blik van de staat, of liever gezegd, staten, die zich het soevereine recht toebedelen mensen in etniciteiten te ordenen. Dat moeten die staten vooral doen, maar zij leveren daarmee slechts één lijn in het spel van grenzen maken. Niemand dwingt de onderzoeker die lijn te volgen, behalve diezelfde staat natuurlijk. Deze staatsvisie is hoogst subjectief. Het is immers de zienswijze van één enkel subject - de soeverein -, maar dit subject is natuurlijk wel dat subject dat met enig succes pretendeert objectief te zijn (Bourdieu 2014).

Juist aan mijn positivistische collega's, wier wetenschapsvisie zo verbonden is met de zuivering van de taal, zou ik willen vragen waarom ze erop staan de categorieën van de staat te verheffen tot waarheid.

\section{Onderzoek voor beleid en debat}

De sociologische nalatigheid rondom 'etniciteit' leidt ertoe dat onderzoeksresultaten niet te interpreteren zijn: ze bevestigen noch weerleggen een gedegen theorie over wat 'geboorteland' doet in de levens van mensen. Waarom wordt dit onderzoek dan al meer dan twintig jaar gedaan? Omdat het aansluit bij de publieke en beleidsmatige definitie van het cultuurprobleem: 'bevolkingsgroepen' mankeert het aan capaciteiten om, met zo min mogelijk beroep op (staats)steun, te overleven in een steeds 'flexibelere' wereld. Daarom wordt, zelfs zonder methodologische basis, het rapporteren van prestatiescores per bevolkingsgroep publiek en beleidsmatig interessant gevonden. Ze demonstreert voornamelijk hoeveel 'last' de belastingbetaler van immigratie zou hebben. Afgezien van het feit dat dit een nogal vernauwende kijk op migratie oplevert en bestendigt, is de vraag natuurlijk waarom die last etnisch gelabeld dient te worden en op welke wijze het verdisconteerd moet worden met de 'baten' van migratie. Zonder een antwoord op die vragen is het lastenonderzoek niet veel meer dan een pr-machine voor, dan weer, anti-migratie en, dan weer, pro-migratie spreekbuizen. 
De etnische labelling van lasten wordt verdedigd door te wijzen op het welbegrepen eigenbelang van 'bevolkingsgroepen': nee, Surinaams-Nederlandse werkloosheid is niet anders dan autochtone werkloosheid, maar zo gaat de redenering - het is in het belang van Surinaamse Nederlanders om de problemen in 'hun' bevolkingsgroep boven tafel te krijgen. Is dat zo? Het is ontegenzeggelijk van groot belang om systematische uitsluiting in kaart te brengen. $\mathrm{Nu}$ is systematiek een van de grote voordelen van een statistische benadering, maar welke systematiek brengt etnische registratie precies aan en leidt deze tot bruikbare inzichten? Hier wreekt zich de onvolkomen conceptualisering van hetgeen 'geboorteland' zou moeten meten.

Wanneer registratie als 'Roemeen', gecontroleerd voor een trits aan variabelen, een effect blijkt te hebben op werkloosheid ... wat zegt dat dan? Gegeven de theoretische vaagheid van 'geboorteland' is het hooguit indicatief voor een mechanisme dat, om verder onbekende redenen, voldoende correleert met de registratie in het GBA. Dit onderzoek voert het beleidsproces allicht naar 'de Roemenen', maar zonder enige verdere aanleiding of oriëntatie. In plaats van deze onwetendheid komt dan al gauw het idee dat 'Roemenen' iets met elkaar delen dat ze als groep vatbaar maakt voor werkloosheid. Dit is een nogal wankele beleidstheorie - ze kan nog alle kanten op - die helpt bij het steeds maar weer opwaarderen van de 'etnische factor', terwijl het effect van 'Roemeen zijn' ook nog aan allerlei andere zaken kan liggen die niet bij 'de Roemenen' te vinden zijn. Zelfs nu opeenvolgende kabinetten doelgroepenbeleid hebben afgezworen, blijft het spreken in 'bevolkingsgroepen' en 'hun' problemen ongehinderd door gaan. Natuurlijk kunnen daadwerkelijke mechanismen achter schijnverbanden verder onderzocht worden. Maar waarom pas nadat de significantie van een holle variabele was aangetoond? Omdat we in zaken van ongelijkheid enkel nog in beweging komen wanneer een probleem tot kenmerk van een 'bevolkingsgroep' is gemaakt?

Etno-statistiek kan, juist vanwege haar luchtledige operationalisering, natuurlijk wel indicatief zijn voor systematische discriminatie en uitsluiting. Wanneer je kans op depressiviteit, longkanker of werkloosheid toeneemt enkel en alleen omdat we de GBA-registratie in het verklaringsmodel opnemen dan roept dat terecht vragen op over het meritocratisch gehalte van Nederland. Die vragen zijn met etno-statistiek verder niet te beantwoorden - mensen lopen niet rond met een GBA-formulier op hun voorhoofd - en lang niet alle vormen van discriminatie of onrecht worden zichtbaar in etno-statistiek. Bovendien gaat het hier om een hypothetische orde waarin alle verschillen tussen burgers zijn verdwenen behalve hun 
merite. Het is de meetlat van de hardwerkende Nederlander. We kunnen de zeggingskracht van dergelijk onderzoek niet te ver doorvoeren: is er zoiets als 'individueel gedrag' zonder verdere bepaling en heeft het zin om mensen zo te ordenen? Marc Elchardus (2015) vraagt zich bijvoorbeeld af waarom de notie van 'merite' die van 'ras' lijkt te naderen: datgene wat overblijft wanneer sociale bepaling is weggezuiverd en waarop mensen boven- en ondergeschikt zouden mogen worden.

Ten slotte kan etno-statistiek precies daar bruikbaar zijn waar de statelijke definitie van verschillen in het spel is. Precies in zoverre de data bepaald worden door de zienswijze van de staat, kunnen die data licht werpen op de verschilwerking van beleid. Het effect van grenzen trekken door de staat, middels migratie- en burgerschapsbeleid, kan zo - alweer gedeeltelijk - worden onderzocht aan de hand van de etnische registratie. Zijn er significante verschillen in toelating, verblijfsstatus, naturalisatie, behandeling en deportatie tussen mensen die staten voor 'Marokkaan', 'Amerikaan' of 'Zweed' houden? Dergelijk onderzoek laat daarmee niet de prestatie van deze of gene 'bevolkingsgroep' zien, maar de verschilwerking die uitgaat van het statelijke grenzen trekken. De etno-statistiek zou op deze manier de staat een spiegel voor kunnen houden, in plaats van bestuurlijke prestatiemetingen te helpen verkondigen (zie bijvoorbeeld Peters et al. 2015).

In de Nederlandse praktijk heeft de focus op etno-statistische kennisvorming geleid tot de institutionalisering van een beleidsobject - 'nietwesterse allochtonen' - wiens collectieve prestaties nauwlettend in de gaten worden gehouden, maar voor wie op basis van dat toezicht verder weinig gedaan kan worden. Er wordt in het felle licht van deze prestatiemetingen van alles gesuggereerd over 'cultuur', maar bar weinig aangetoond. Zoals ik heb laten zien: dat kan aan de hand van onderzoek naar 'bevolkingsgroepen' helemaal niet.

De commissie Blok concludeerde reeds: nieuwkomers hebben zich een positie in Nederland verworven ondanks het gevoerde beleid (Commissie Blok 2004). De factor 'geboorteland' kan immers niet met beleid worden beïnvloed anders dan proberen grenzen te sluiten voor bepaalde mensen of mensen anders te categoriseren. De landsgrenzen worden al geruime tijd omgebouwd tot zeef om mensen te weren die 'ongeschikt' worden geacht voor 'het moderne leven'. Leven en dood worden bepaald door 'afkomst'. Over het aanpassen van beleidscategorieën woedt zo af en toe een discussie, waarbij serieus gepleit wordt voor het registreren van 'derde-' of zelf 'vierde-generatie allochtonen'. Hier wordt de registratie van migratiegeschiedenissen, die toch al wortels had in koloniaal bestuur en essentia- 
listische rassen- en cultuuropvattingen (Stoler 2010; Hondius 2011; vgl. Verwey-Jonker 1973), een vorm van raciale demografie.

I am less interested in how repetition spawns variants as a matter of course than in the possibility of a counterdiscourse that emerges in the midst of break-

down, animating the remnants of a broken ideological machine for critical purposes.

- Judith Butler (2015: 37)

\section{$4 \quad$ Alsnog cultuur?}

Wat valt er door sociologen dan wel over cultuur te zeggen? Of misschien moeten we vragen: wat valt er nog voor cultuur te zeggen? Cultuur wordt terecht verguisd in de sociale wetenschap (Lemaire 1986). Al dan niet gemeten aan de hand van 'geboorteland', moet het staan voor een onhanteerbare kluwen van 'sociale invloeden' (Kuper 1999). Het duidt even veel op 'expressie', 'vrije tijd', 'de publieke sfeer', 'de private sfeer', 'overtuigingen', 'opvattingen', 'claims', 'discoursen', 'betekenis', 'taal', 'socialisatie', 'idealen', 'waarden', 'sublimatie', 'beleving', 'interpretatie', 'gezin', 'familie', 'groepsleven', 'gemeenschap', 'gebruiken', 'tradities', 'normen', 'uitdrukking', 'impressie', 'context' of 'omgeving'. Weg ermee zou je zeggen.

Waar al deze connotaties op willen duiden, is niet totaal ongewis: ze worden bij elkaar gehouden door de idee dat 'sociale uitkomsten' niet enkel bepaald worden door de samenkomst van anonieme 'factoren' maar ook nog door manieren van doen. Sociale situaties worden niet enkel beslist en besloten door hun discrete onderdelen - gemeten als 'factoren' - maar ook nog door de manier waarop geanticipeerd wordt op een zeker besluit van die situaties terwijl ze zich voordoen (zie vooral Austin 1962). Pas wanneer er geanticipeerd wordt op een vergadering aan de hand van gebaren - 'hierbij open ik deze vergadering' -, worden de stoelen, tafels, carrières, lijven, gebouwen, kennis, diploma's etc. een serie 'factoren' bij die vergadering. Dit anticiperen wordt ook wel performativiteit genoemd en vormt de conceptuele motor van de hedendaagse, vaak pragmatistische cultuurtheorie (zie Butler 1993; Alexander 2004; Latour 2005; Bell 2007; Somers 2008).

Zelfs zouden we het onbruikbare concept 'bevolkingsgroep' achter ons laten, dan nog verhoudt het bestaande programma van verklarende sociologie zich moeilijk tot performativiteit. Het probeert anticipaties namelijk juist voor te zijn: hoe waarschijnlijker een bepaalde uitkomst gemaakt kan 
worden - verklaarde variantie -, hoe beter. De vormende rol van performativiteit is enkel reststof. Juist daarom zoekt dit programma de 'culturele factor' in die zaken waarvan verondersteld wordt dat ze in principe onbeslist zijn: in de sfeer van de individuele autonomie of 'keuzevrijheid'. Cultuur is dan te vinden bij precies die zaken waarvan 'moderne mensen' veronderstellen dat het individu ze kan en mag veranderen: denkbeelden, gedrag in de publieke en private sfeer, seksualiteit, hoop, verlangen, religie, vriendschappen, inzet, relaties, vrije tijd etc.

Omdat 'culturele verklaringen' gaan over zaken die 'het moderne individu' geacht wordt te kunnen en mogen veranderen, sluiten 'culturele verklaringen' naadloos - en dus onfeilbaar - aan bij de problematisering van 'cultuur' zoals die vanaf de jaren zeventig vorm krijgt. 'Cultuur' is dan al die zaken die vrij-geachte individuen wel kunnen en mogen, maar niet willen of durven veranderen. 'Cultuur' is de tijdelijke inperking van onstuitbare 'flexibiliteit'. De verantwoordelijkheid voor 'culturele' effecten wordt zo klaarblijkelijk terecht - gelegd bij een verinnerlijkte weerstand tegen verandering. Daarom krijgt 'cultuur' uiteindelijk een psycho-moralistische duiding. De oplossing is het breken of verleggen van weerstand: mensen dienen te laten zien dat zij zich voldoende identificeren met het vrijgemaakte individu dat in fel oranje aan ons voorgesteld wordt (Mellink 2014; Van Reekum 2014). Geen wonder dat nagenoeg ieder serieus beleidsvoorstel over 'integratie' neerkomt op een vorm van klassikale instructie. Cultuurverandering is morele dressage.

Wat kunnen we nu wel met een performatief cultuurbegrip? Daar is al een hoop over gezegd (Garfinkel 1967) en nog te zeggen, maar in het kader van de voorgaande discussie is de belangrijkste les de volgende. De rol van cultuur is niet te begrijpen zonder een gedegen beschrijving van geanticipeerde toekomsten. Verbeeldingen van die toekomsten moeten op zichzelf beschouwd worden en niet als min of meer adequate reacties op of gevolgen van 'reële condities' in de mentaliteit van 'personen'. Juist daarom zijn 'attitudes', 'motieven', 'intenties', 'strategieën' of 'redenen' geen goede vervanging voor hetgeen performativiteit aanduidt. Ze maken van anticipatie toch weer een gesocialiseerde houding of gewoonte. Performativiteit draait om manieren van anticiperen die in iedere situatie aan de hand zijn en valt dus noch samen met 'habitus', noch met 'keuze'.

De groepslogica van het gangbare cultuurbegrip werkt hoogst verwarrend: cultuur wordt niet langer in het licht van verbeelde toekomsten geanalyseerd maar als min of meer versteende gedragingen van populaties: 'zo doen zij dat'. Dergelijke verklaringen kunnen enkel terecht komen in tautologieën en just so stories, waarin 'cultuur' precies de vorm van de te 
verklaren uitkomst aanneemt. Wanneer performativiteit beschreven wordt in het licht van de toekomst, kan dit voorkomen worden. Ter afsluiting een voorbeeld.

Uit onderzoek naar carrières van jongeren in de economie van verdovende middelen, wapens en vrouwen is op te maken dat een cruciale schakel gevormd wordt door de anticipatie op vernedering die voortdurend verbeeld wordt in de levens van deze gangmakers. Dit imaginair van, voornamelijk mannelijke, vernedering blijkt van groot belang in het verklaren van bepaalde vormen van criminaliteit. Natuurlijk is het pochen, steken en stelen 'aangeleerd' (vgl. Van San 2001; Siegel et al. 2009). Het vergt oefening en instructie. Dat aanleren is goed te vatten in situationele, belichaamde en terugkerende praktijken die leiden tot de bestendiging van bepaalde handelingswijzen (zie bijvoorbeeld De Jong 2007; Paulle 2013). Er is echter ook nog een anticipatie op vernedering die de motor van onderschikking en (uitgesteld) falen draaiende houdt. Het is anticipatie die de bundel van 'factoren' - buurt, mannelijkheid, kennissen, school, gezin, geld, vriendschappen, identificaties, fysiek geweld, beleid, segregatie etc. aan elkaar knoopt. Deze verklaring geeft aanleiding tot een probleemanalyse die vele malen scherper georiënteerd is dan de volkenkundige verdwaling waartoe 'bevolkingsgroep' leidt.

Natuurlijk: jongeren zullen redenen moeten hebben om niet te anticiperen op vernedering. Waarom wordt ze deze rationaliteit ontzegd? Maar meer nog: er zullen alternatieve verbeeldingen van de toekomst beschikbaar moeten zijn. Bijvoorbeeld een waarin de liberale waanzin van 'eigen verantwoordelijkheid' en 'invechten' wordt ontmaskerd en bekritiseerd, waarin strijd tegen ongelijkheid een politieke of zelfs profetische lading kan krijgen. De Black Lives Matter-beweging in de VS is een goed voorbeeld, zo ook het recente activisme tegen Nederlands racisme. Daar worden de 'factoren' van vernedering op een alternatieve manier aaneengeschakeld. Dat is cultuur. Ten slotte roept deze benadering de vraag op waar het imaginair van mannelijke vernedering nog meer in het spel is en, onder andere condities, leidt tot gelijksoortige loyaliteiten aan een 'eigen club' en het veronachtzamen van de gewelddadige consequenties die gedrag - al dan niet aan het roer van een financiële instelling - voor anderen heeft. Ik zou beginnen bij de inheemse studentencorpsen. 


\section{Noten}

1. Zie voor kritieken: Philipse (2016), Van der Meer (2016a), Van der Meer (2016b) en Jennissen, Dagevos en Engbersen (2016).

2. Het ideaal van nomothetisch-deductieve wetenschap is niet het mijne. Maar mogen wij van haar beoefenaren vragen zich aan de eigen regels te houden?

3. In het geval van meer, dan alleen als de discrete optelling van één en nog één.

\section{Literatuur}

Alexander, J.C. (2004) Cultural Pragmatics: Social Performance Between Ritual and Strategy. Sociological Theory, 22(4): 527-573.

Austin, J.L. (1962) How To Do Things With Words. Cambridge: Harvard University Press.

Barker, M. (1981) The New Racism: Conservatives and the Ideology of the Tribe. Toronto: Junction Books.

Baumann, G. (1996) Contesting Culture: Discourses of Identity in Multi-ethnic London. Cambridge: Cambridge University Press.

Baumann, G. en A. Gingrich (2004) Grammars of identity/alterity: a structural approach. Oxford: Berghahn Books.

Bell, V. (2007) Culture and performance: the challenge of ethics, politics and feminist theory. London: Berg.

Berg, M. van den (2016) 'Activating' those that 'lag behind': space-time politics in Dutch parenting training for migrants. Patterns of Prejudice, 50(1): 21-37.

Berg-Eldering, L. van den (1986) Van gastarbeider tot immigrant: Marokkanen en Turken in Nederland, 1965-1985. Alphen aan den Rijn: Samsom.

Boersma, S. en W. Schinkel (2015) Imagining society: Logics of visualization in images of immigrant integration. Environment and Planning D: Society and Space, 33(6): 1043-1062.

Bonjour, S. (2009) Grens en gezin: Beleidsvorming inzake gezinsmigratie in Nederland, 1955-2005. Amsterdam: Amsterdam University Press.

Bosma, U. (2013) Why is there no post-colonial debate in the Netherlands? In: U. Bosma (red.) Post-colonial Immigrants and Identity Formations in the Netherlands. Amsterdam: Amsterdam University Press, 193-212.

Bourdieu, P. (2014) On The State. Cambridge: Polity.

Brubaker, R. (2004) Ethnicity without groups. Cambridge: Harvard University Press.

Buiks, P.E. (1983) Surinaamse jongeren op de Kruiskade: Overleven in een etnische randgroep. Deventer: Van Loghum Slaterus.

Butler, J. (1993) Bodies that Matter: On the Discursive Limits of Sex. London: Routledge.

Butler, J. (2015) Theatrical Machines. differences, 26(3): 23-42.

Comaroff, J.L. en J. Comaroff (2009) Ethnicity, Inc. Chicago: University of Chicago Press.

Commissie Blok (2004) Bruggen Bouwen. Tweede Kamer der Staten-Generaal, vergaderjaar 20032004, 28689 nrs. 8-9.

Couwenberg, S.W. (1982) 'Het vraagstuk der etnische minderheden, themanummer'. Civis Mundi, $21(5)$.

Derksen, A. en L. Verplanke (1987) Geschiedenis van de onmaatschappelijkheidsbestrijding in Nederland, 1914-1970. Amsterdam: Boom.

Dijk, T.A. van (1992) Discourse and the denial of racism. Discourse \& Society, 3(1): 87-118.

Duyvendak, J.W., T. Pels en R. Rijkschroeff (2009) A multicultural paradise? The cultural factor in 
Dutch integration policy. In: J.L. Hochschild en J.H. Mollenkopf (red.) Bringing Outsiders In. Transatlantic Perspectives on Immigrant Political Incorporation. Ithaca: Cornell University Press, 129-139.

Duyvendak, J.W., R. van Reekum, F. el-Hajjari en C. Bertossi (2013) Mysterious multiculturalism. The risks of using model-based indices for making meaningful comparisons. Comparative European Politics, 11: 599-620.

Elchardus, M. (2015) Dubieuze merite, reëel precariaat: een sociaal en cultureel rapport dat het verschil zou kunnen maken. Sociologie, $11(3 / 4)$.

Entzinger, H. en P. Scholten (2015) The Interplay of Knowledge Production and Policymaking: A Comparative Analysis of Research and Policymaking on Migrant Integration in Germany and the Netherlands. Journal of Comparative Policy Analysis: Research and Practice, 17(1): 60-74.

Eriksen, T.H. (2012) Ethnicity. Hoboken: John Wiley \& Sons.

Essed, P. (1984) Alledaags Racisme. Amsterdam: Feministische Uitgeverij Sara.

Essed, P. (1994) Diversiteit: vrouwen, kleur en cultuur. Amsterdam: Ambo.

Essed, P. en K. Nimako (2006) Designs and (Co) Incidents Cultures of Scholarship and Public Policy on Immigrants/Minorities in the Netherlands. International Journal of Comparative Sociology, 47(3-4): 281-312.

Ferrier, J.M. (1985) De Surinamers. Bussum: Coutinho.

Fields, B.J. en K. Fields (2012) Racecraft: The soul of inequality in American life. London: Verso Books.

Gabriels, R.H. (2001) Intellectuelen in Nederland: publieke controversen over kernenergie, armoede en Rushdie. Amsterdam: Boom.

Garfinkel, H. (1967) Studies in ethnomethodology. Upper Saddle River: Prentice Hall.

Gouda, F. (2008) Dutch culture overseas: Colonial practice in the Netherlands Indies, 1900-1942. Sheffield: Equinox Publishing.

Groenendijk, K. (2008) Allochtonen of burgers: definitiemacht in debat en wetgeving over immigranten. In: J.W. Duyvendak, G. Engbersen, M. Teeuwen en I. Verhoeven (red.) Macht en verantwoordelijkheid. Essays voor Kees Schuyt. Amsterdam: Amsterdam University Press, 101112.

Hacking (2007) Kinds of people: moving targets. Proceedings of the British Academy, 151: 285-318.

Hall, S. (1996) Gramsci's relevance for the study of race and ethnicity. In: D. Morely en K. Chen (red.) Stuart Hall: Critical dialogues in cultural studies. London: Routledge, 411-440.

Hondius, D. (2011) Access to the Netherlands of enslaved and free Black Africans: exploring legal and social historical practices in the sixteenth-nineteenth centuries. Slavery \& Abolition, 32 (3): 377-395.

Houdt, F. van (2014) Governing Citizens: The government of citizenship, crime and migration in the Netherlands. Rotterdam: Erasmus University Rotterdam, proefschrift.

Jennissen, R., J. Dagevos en G. Engbersen (2016) Migranten crimineler? Niet selectief shoppen in onze cijfers. NRC Handelsblad, 6 februari.

Jones, G.R. (2007) Tussen onderdanen, rijksgenoten en Nederlanders. Nederlandse politici over burgers uit Oost en West en Nederland 1945-2005. Amsterdam: Rozenberg.

Jong, J.D. de (2007) Kapot moeilijk. Een Etnografisch Onderzoek naar Opvallend Delinquent Gedrag van 'Marokkaanse' Jongens. Amsterdam: Aksant.

Kennedy, J.C. (1995) Nieuw Babylon in aanbouw: Nederland in de jaren zestig. Amsterdam: Boom.

Krebbekx, W., R. Spronk en A. M'Charek (2013) Categorieën als verschilmakers: etnische praktijken in onderzoek naar jongeren en seksualiteit. Sociologie, 9(3/4): 344-366.

Kuper, A. (1999) Culture: The Anthropologists' Account. Cambridge: Harvard University Press.

Laarman, C. (2013) Oude onbekenden: Het politieke en publieke debat over postkoloniale migranten in Nederland, 1945-2005. Hilversum: Verloren. 
Lamont, M. en V. Molnar (2002) The Study of Boundaries Across the Social Sciences. Annual Review of Sociology, 28: 167-195.

Latour, B. (2005) Reassembling the social: An introduction to Actor-Network Theory. Oxford: Oxford University Press.

Lemaire, T. (1976) Over de waarde van kulturen; een inleiding in de kultuurfilosofie. Amsterdam: Ambo.

Lucassen, L. en J. Lucassen (2011) Winnaars en verliezers: een nuchtere balans van vïfhonderd jaar immigratie. Amsterdam: Bert Bakker.

Lucassen, L. en J. Lucassen (2015) The Strange Death of Dutch Tolerance: The Timing and Nature of the Pessimist Turn in the Dutch Migration Debate. The Journal of Modern History, 87(1): 72101.

M'Charek, A. (2013) Beyond fact or fiction: On the materiality of race in practice. Cultural Anthropology, 28(3): 420-442.

Meer, T. van der (2016a) De onzin van twee minuten DWDD: Hoezo, 10.000 binnengehaalde zedendelinquenten? Verkregen op 21 maart 2016, hstukroodvlees.nl/de-onzin-van-2-minutendwdd-hoezo-10-ooo-binnengehaalde-zedendelinquenten/.

Meer, T. van der (2016b) En toen had opeens iedereen een mening over statistiek: vluchtelingen en criminaliteitscïfers. Verkregen op 21 maart 2016, stukroodvlees.nl/en-toen-had-opeens-iedereen-een-mening-over-statistiek-vluchtelingen-en-criminaliteitscijfers/.

Mellink, A.G.M. (2014) Worden zoals wij. Onderwijs en de opkomst van de geïndividualiseerde samenleving sinds 1945. Amsterdam: Wereldbibliotheek.

Mepschen, P., J.W. Duyvendak en E. Tonkens (2010) Sexual politics, orientalism, and multicultural citizenship in the Netherlands. Sociology, 44(5): 962-979.

Molleman, H. (2003) Het minderhedenbeleid in retrospectief. Socialisme \& Democratie, 1(2): 62 66.

Paulle, B. (2013) Toxic schools: high-poverty education in New York and Amsterdam. Chicago: University of Chicago Press.

Peters, F., M. Vink en H. Schmeets (2015) The ecology of immigrant naturalisation: a life course approach in the context of institutional conditions. Journal of Ethnic and Migration Studies, 123.

Philipse, S. (2016) De feitenvrije demonisering van vluchtelingen bij DWDD. Verkregen op 21 maart 2016, medium.com/@sanderphilipse/hoe-dwdd-migranten-feitenvrij-laat-demoniseren48a6bgbba22d\#.gbkbwkb5p.

Prins, B. (2004) Voorbij de onschuld. Het debat over de multiculturele samenleving. Amsterdam: Van Gennep.

Rath, J. (1992) De tegenbedoelde effecten van de geleide integratie van 'etnische minderheden'. Beleid \& Maatschappij, 19(5): 252-265.

Reekum, R. van (2014) Out of Character: Debating Dutchness, Narrating Citizenship. Amsterdam: University of Amsterdam.

Regt, A. de (1984) Arbeidersgezinnen en beschavingsarbeid: ontwikkelingen in Nederland, 1870-1940: een historisch-sociologische studie. Amsterdam: Boom.

Ruppert, E. (2012) Seeing Population: Census and Surveillance by Numbers. In: K. Ball, K. Haggerty en D. Lyon (red.) Routledge International Handbook of Surveillance Studies. London: Routledge, 209-216.

San, M. van (1998) Stelen en steken: delinquent gedrag van Curaçaose jongens in Nederland. Amsterdam: Het Spinhuis.

Schinkel, W. (2007) Denken in een tijd van sociale hypochondrie, aanzet tot een theorie voorbij de maatschappij. Zoetermeer: Klement. 
Schinkel, W. (2013) The imagination of 'society' in measurements of immigrant integration. Ethnic \& Racial Studies, 36(7): 1142-1161.

Scholten, P. (2011) Framing Immigrant Integration: Dutch Research-policy Dialogues in Comparative Perspective. Amsterdam: Amsterdam University Press.

Schrover, M. (2010) Pillarization, multiculturalism and cultural freezing, Dutch migration history and the enforcement of essentialist ideas. BMGN-Low Countries Historical Review, 125(2/3): 329-354.

Siegel, D., F. Bovenkerk en F. van Gemert (2009) Culturele criminologie. Den Haag: Boom Juridische Uitgevers.

Somers, M.R. (1995a) What's Political or Cultural about the Political Culture Concept? Toward an Historical Sociology of Concept Formation. Sociological Theory, 13(2): 113-144.

Somers, M.R. (1995b) Narrating and Naturalizing Civil Society and Citizenship Theory: The Place of Political Culture and the Public Sphere. Sociological Theory, 13(3): 229-274.

Somers, M.R. (2008) Genealogies of Citizenship: Markets, Statelessness, and the Right to Have Rights. Cambridge: Cambridge University Press.

Stoler, A.L. (2010) Along the archival grain: Epistemic anxieties and colonial common sense. Princeton: Princeton University Press.

Tinnemans, W. (1994) Een gouden armband: Een geschiedenis van Mediterrane immigranten in Nederland (1945-1994). Utrecht: Nederlands Centrum Buitenlanders.

Uitermark, J. (2012) Dynamics of Power in Dutch Integration Politics: From Accommodation to Confrontation. Amsterdam: Amsterdam University Press.

Valk, I. van der (2002) Difference, Deviance, Threat? Mainstream and Right-Extremist Political Discourse on Ethnic Issues in the Netherlands and France (1990-1997). Amsterdam: Aksant.

Verkaaik, O. (2009) Ritueel burgerschap: een essay over nationalisme en secularisme in Nederland. Amsterdam: Aksant.

Vermeulen, H. (1984) Etnische groepen en grenzen. Chinezen, Surinamers en Turken. Weesp: Het Wereldvenster.

Verweij, A.O. (1997) Vaststelling van etnische herkomst in Nederland. De BiZa-methode nader bekeken. Rotterdam: Instituut voor Sociologisch-Economisch Onderzoek.

Verwey-Jonker, H. (1973) Allochtonen in Nederland: beschouwingen over de: gerepatrieerden, Ambonezen, Surinamers, Antillianen, buitenlandse werknemers, Chinezen, vluchtelingen, buitenlandse studenten in onze samenleving. Den Haag: Staatsuitgeverij.

Vink, M. (2007) Dutch 'Multiculturalism' beyond the pillarisation myth. Political Studies Review, 5: 337-350.

Vries, G. de (1977) Sociale orde, regels en de sociologie; een wetemchapsfilosofischonderzoek naar de theorievorming in de sociologie. Amsterdam: Boom.

Vuijsje, H. (1986) Vermoorde Onschuld: Etnisch verschil als Hollands taboe. Amsterdam: Bert Bakker.

Weiner, M.F. (2015) The Demography of Race and Ethnicity in The Netherlands: An Ambiguous History of Tolerance and Conflict. In: R. Sáenz, N. Rodriguez en D.G. Embrick (red.) The International Handbook of the Demography of Race and Ethnicity. New York: Springer, 575596.

Wekker, G. en H. Lutz (2001) Een hoogvlakte met koude winden. De geschiedenis van het genderen etniciteitsdenken in Nederland. In: M. Botman, N. Jouwe en G. Wekker (red.) Caleidoscopische visies. De zwarte, migranten en vluchtelingenvrouwenbeweging in Nederland. Amsterdam: KIT.

Werf, S. van der (1994) Allochtonen: een inleiding. Bussum: Coutinho.

Wijk, A. van en A. Blokland (2006) Zedendelinquentie en etniciteit. Een exploratief onderzoek op basis van politiegegevens. Mens \& Maatschappij, 83(2): 109-127. 
Wimmer, A. en N. Glick Schiller (2002) Methodological nationalism and beyond: nation-state building, migration and the social sciences. Global networks, 2(4): 301-334.

Yanow, D. en M. van der Haar (2013) People out of place: Allochthony and autochthony in Netherlands identity discourse - metaphors and categories in action. Journal for International Relations and Development, 16(2): 227-261.

\section{Over de auteur}

Rogier van Reekum is postdoctoraal onderzoeker aan de afdeling Bestuurskunde en Sociologie van de Erasmus Universiteit Rotterdam. Hij is onderdeel van het Monitoring Modernity project (ERC starting grant) onder leiding van prof. dr. Willem Schinkel. Daar doet hij onderzoek naar de visualisering van irreguliere migratie in Europa. Rogier schreef een proefschrift (cum laude) aan de AISSR (Universiteit van Amsterdam) over publieke en politieke debatten rondom Nederlanderschap (1972-2008) en publiceerde over nationalisme, plaats, burgerschapspolitiek, immigratiebeleid en onderwijs. Hij is redacteur bij Sociologie en Krisis, tijdschrift voor actuele filosofie.

E-mail:vanreekum@fsw.eur.nl 
